\title{
A new structure for the Journal of Medical Ethics
}

Julian Savulescu The Murdoch Childrens Research Institute and the University of Melbourne, Australia

Over the next few issues, you will notice some changes to the Fournal of Medical Ethics. Box 1 summarises the new structure for the journal.

Current Controversies will briefly describe a current issue of public interest. Informal comment will be invited from a number of commentators from a variety of disciplines. The goal of this section is to provide a publicly accessible resource to promote informed general debate. There will be free web access to the Current Controversies.

The Leading Article will be a longer (up to 5500 words), sometimes more philosophical, article, which will generally be invited. It may also be an important piece of original empirical research. Occasionally, commentaries will be invited to accompany the leading article. There will be free web access to the Leading Article.

The peer reviewed Original Contributions will continue. These will occasionally be grouped into thematic minisymposia. The goals for this section are to aim for speedier review and publication, shorter articles (ideally less than 3500 words) which include aids for the reader (boxes, algorithms, flow charts, lift out messages, etc).

A number of new Special Subsections will be introduced with new associate editor(s) assigned to each section. The goal of these articles is to help people with an interest in some aspect of medical ethics. These will be peer-reviewed.

Teaching and Learning Medical Ethics is aimed at those who wish to know more about the basic theories and approaches to medical ethics or who are teaching medical ethics. It will have a strong "how to" focus, with summaries of concepts and theories, model lectures/presentations, instructions on how to teach ethics or give seminars, and answers to commonly asked questions. It will include professional education including core competencies in medical ethics.

Clinical Ethics aims to provide those involved in clinical ethics with updates on developments in that area, relevant articles and case conferences. Case discussions are particularly sought.

Research Ethics aims to provide resources for those on research ethics committees as well as articles of relevant interest.

Global Medical Ethics will aim to promote the discussion of medical ethics at a global level. This section will include articles on issues of special interest to those outside North America, Western Europe, Australia and New Zealand.

Ethics, Law and Medicine will cover developments in medical law which of are of interest to the medical profession and those working in medical ethics. These will include relevant legal cases, new legislation and articles.

A Review Essay will be an article-length analysis of a book or paper, or a series of books or papers, which will be peer reviewed. Commentaries or responses may be invited.

The Book Review section will include shorter reviews, as well as tables of best books relevant to a particular topic.

\section{Box 1. Summary of the new structure of the journal}

\section{Regular sections}

Editorial

Guest Editorial

Current Controversies (free web access)

Leading Article (free web access)

Peer reviewed original contributions

\section{New special sections}

- Teaching and Learning Ethics

- Clinical Ethics

- Research Ethics

- Global Medical Ethics

- Law, Ethics and Medicine

- Review Essay

Ethics Briefings

Book Reviews

Letters and eLetters

News and notes

\section{Occasional sections}

Brief Reports

Debate

Point of view

Medical Student Essay

Glossary 
Ethics Briefings, provided by the British Medical Association, will now include electronic updates to previous briefings.

Brief Reports will be a new section which will briefly report events, reports, legal developments and the results of empirical research from around the world. These will be up to 750 words.

Point of View will express a personal opinion of significant interest to the medical ethics community (up to 750 words)

A Medical Student Essay of up to 1850 words will be published occasionally. This may be the result of elective work in medical ethics.

The journal encourages electronic correspondence, especially responses to articles. These can be posted immediately as eLetters. Some eLetters will be selected for reproduction in the paper version of the journal. Letters can be up to 400 words.
Debate will include articles which have an invited contrary point of view, or responses to previously published articles.

A Glossary will occasionally appear which will define a core term in medical ethics and provide discussion of it (of up to 400 words).

Readers are welcome to submit to any section. The Editors, Deputy Editor and Associate Editors may allocate submitted material to the most relevant section.

There will also be greater integration with the $B M F$ and other BMF Publishing Group (BMJPG) journals. Shortened versions of the leading article, comments on current controversies or other articles may appear in the BMF or other BMJPG journals (with appropriate referencing). Ethics commentaries on articles in the BMJPG journals will be actively encouraged.

\section{News and notes}

\section{International Symposium: The State of ART Regulation- International Perspectives}

A one-day international symposium, The State of ART Regulation-International Perspectives, will be held in Melbourne, Victoria, Australia on Friday November 232001.

Participants at the symposium will hear from expert speakers about the status of regulation of assisted reproductive technology in different countries around the world and discuss the challenges faced by those regulating and accrediting infertility services. The symposium will be held prior to the 17 th world Congress on Fertility and Sterility, which is scheduled for November 242001 to December 1 2001

Presentations providing an overview of Europe, New Zealand, the USA and Australia are now confirmed, and other presentations are being finalised. The afternoon programme will consider the vexed issues of donor procedures, eligibility to access assisted reproduction, and embryo research.
Papers are now being called for the afternoon session of the symposium, which will address the three areas above, in concurrent programme sessions. If you are interested in presenting a paper, please email hszoke@ita.org.au for an outline of the programme themes.

Registrations are also now being called for the symposium. Only one hundred places are available so early registration is advised. For a copy of the registration form please email: hszoke@ita.org.au or write to: The State of ART Symposium, c/- ITA, 30/570 Bourke Street, Melbourne, Victoria, Australia 3000. The registration fee will be $\$ 100.00$ and the venue will be University College, College Crescent, Parkville.

For further information please contact: Helen Szoke, ITA, 30/570 Bourke Street, Melbourne, Victoria, Australia 3000. Ph: 6138601 5250; fax: 613 8601 5277; email: hszoke@ita.org.au 